\title{
Precision Fast Kickers for Kiloampere Electron Beams
}

\author{
YJ. (Judy) Chen \\ GJ. Caporaso \\ J.T. Weir
}

This paper was prepared for submittal to the

1999 Particle Accelerator Conference

New York, NY

March 29-April 2, 1999

\section{March 1999}

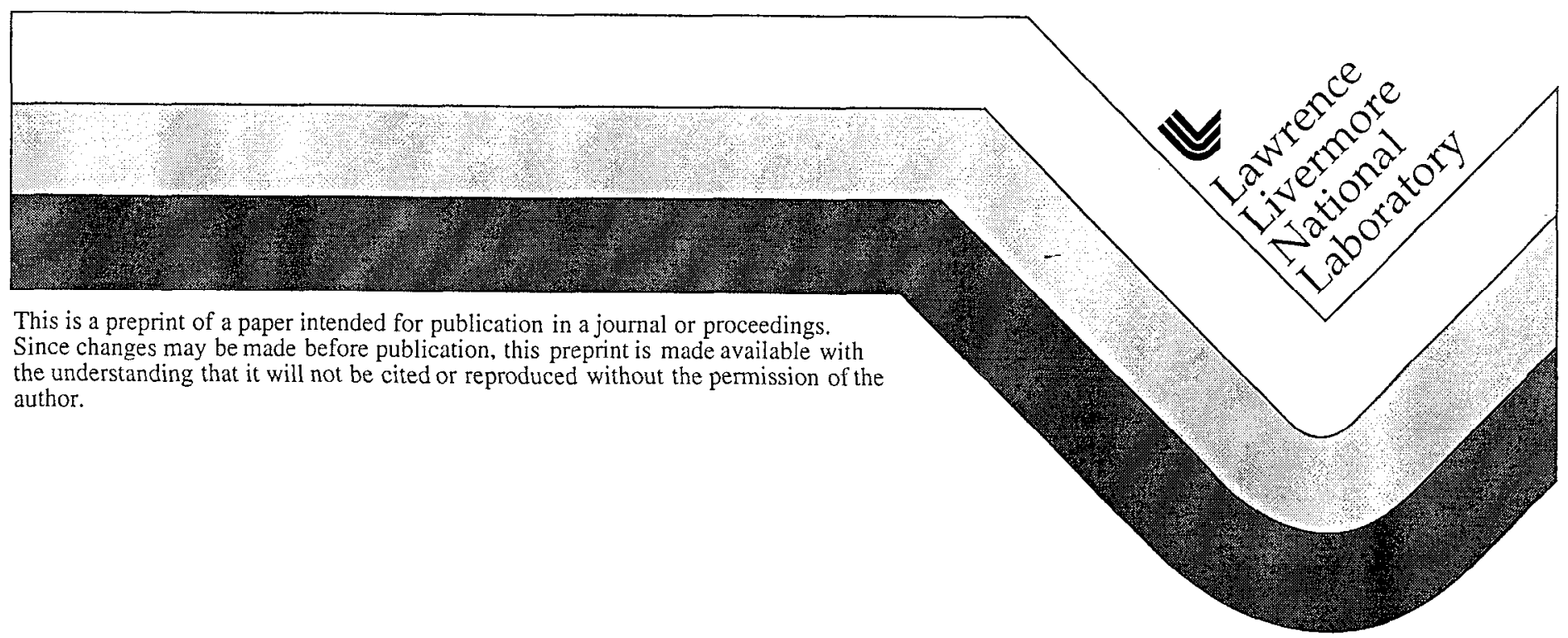




\section{DISCLAIMER}

This document was prepared as an account of work sponsored by an agency of the United States Government. Neither the United States Government nor the University of California nor any of their employees, makes any warranty, express or implied, or assumes any legal liability or responsibility for the accuracy, completeness, or usefulness of any information, apparatus, product, or process

disclosed, or represents that its use would not infringe privately owned rights. Reference herein to any specific commercial product, process, or service by trade name, trademark, manufacturer, or otherwise, does not necessarily constitute or imply its endorsement, recommendation, or favoring by the United States Government or the University of California. The views and opinions of authors expressed herein do not necessarily state or reflect those of the United States Government or the University of California, and shall not be used for advertising or product endorsement purposes. 


\section{Precision fast kickers for kiloampere electron beams \\ Y. J. (Judy) Chen}

\section{Abstract}

These kickers will be used to make fast dipoles and quadrupoles which are driven by sharp risetime pulsers to provide precision beam manipulations for high current $\mathrm{kA}$ electron beams. This technology will be used on the $2^{\mathrm{ml}}$ axis of the DARHT linac at LANL. It will be used to provide 4 micropulses of pulse width 20 to 120 nsec. selected from a $2 \mu \mathrm{sec}$., $2 \mathrm{kA}, 20 \mathrm{MeV}$ macropulse. The fast pulsers will have amplitude modulation capability [1] to compensate for beam-induced steering effects [2] and other slow beam centroid motion to within the bandwidth of the kicker system [3]. Scaling laws derived from theory will be presented along with extensive experimental data obtained on the test bed ETA-II [4].

\section{INTRODUCTION}

The-kicker system is the principal element of the beam transport section of DARHT-II. It is similar in design to stripline beam position monitors. There are four equal size electrodes enclosed within a vacuum housing that has a DC bias magnetic dipole wound over the enclosure. An opposite pair of electrodes is driven by fast amplifiers through transit time isolated cables to provide beam deflection. The other two electrodes are terminated at their matched impedance. A drift space between the kicker and a DC septum magnet provides additional separation between the switch positions. The bias dipole is turned on at all times to deflect the beam into a dump. When an $x$-ray pulse is desired the pulsers active and overcome the bias dipole force allowing the beam to steer straight ahead through the rest of the transport section and on to the converter target.

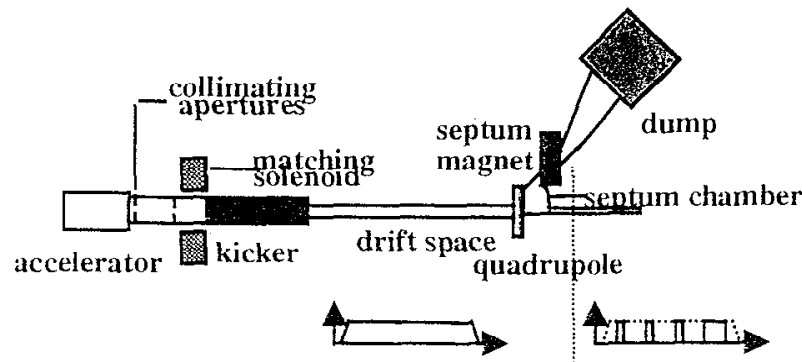

Fig. 1 Kicker system beam line layout

\section{SCALING LAWS}

The following is a list of scaling laws that relate performance of the system to the kicker geometry (see Fig. 2), pulser capacity, and beam parameters.
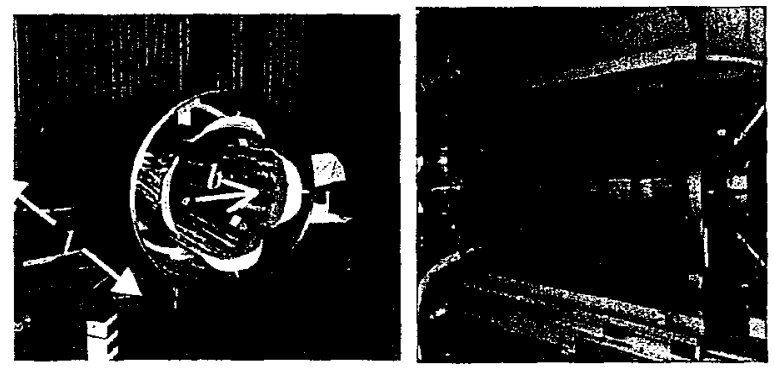

Figure 2: Cross-sectional view of kicker and completed assembly on beam line. The red tapes hold the bias dipole windings.

\subsection{Applied "kick"}

The following proportionalities relate the amount of output displacement and angle to the dimensions of the kicker and energy of the beam. The characteristic voltage $V_{0}$ [3] is a parameter used in determining the amount of kick. Specifically the ratio of the amount of displacement to the length of the kicker is $V_{p} / V_{0}$ where $V_{p}$ is a square output from the pulsers.

$$
\begin{aligned}
V_{0} & \propto \frac{b}{l} \text { and } Z_{k} \\
x & \propto \frac{l^{2}}{b} \text { and } Z_{k} \\
\angle & \propto \frac{l}{b} \text { and } Z_{k}
\end{aligned}
$$

where $Z_{k}$ is the dipole impedance of the kicker and determined by the radius of the striplines and outer vacuum chamber.

\subsection{Beam-induced steering effects}

The critical current, $I_{i}$, as derived in [2], is a parameter used to measure the amount of beam-induced steering the kicker adds to the beam. One generally would like to design it such that $I_{n}<<$, to minimize this effect where $I_{\text {, }}$ is the beam current. Assuming that this is true, the following laws can be used.

t

This work was performed under the auspices of the U.S. Department of Energy by LLNL under contract W-7405ENG-48.

†E-mail: chen29@Ilnl.gov 


$$
\begin{gathered}
I_{c} \propto \frac{b^{2}}{l^{2}} \text { and } \frac{1}{Z_{k}} \\
\text { amplitication in } x \propto 1+\frac{I_{i}}{I_{c}} \\
\text { amplification in } \angle \propto \sqrt{\frac{2 I_{b}}{I_{c}}} \\
\text { amplification in } k_{\perp} \propto 1+\frac{I_{b}}{6 I_{c}}
\end{gathered}
$$

\subsection{Quadrupole shaping}

The kicker can act like a quadrupole lens, shaping the beam with a dynamic controllable quadrupole electric field. Two pulsers connected on opposite plates similar to the dipole contiguration excite the plates with the same polarity voltage signals. The strength which is defined to be the field gradient multiplied by the length of the lens can also be applied here.

$$
\frac{d E}{d x} l \propto \frac{l}{b^{2}}
$$

\subsection{Emittance}

If we assumed a small perturbation from the particle trajectory due to sextupole fields that exist in an activated kicker, we can deduce a simple scaling law for emittance growth through the kicker structure.

$$
\Delta \varepsilon \propto\left(\frac{l}{b^{3}}\right)^{2}, \frac{1}{\mathrm{Z}_{\mathrm{k}}{ }^{2}} \text {, and } R_{0}{ }^{h}
$$

where $R_{0}$ is the beam radius assumed to be constant through the kicker. One can see the size of the bore and distance of the strip lines from the center dominate the emittance growth through the kicker.

\subsection{Rise time of beam}

We can use the dynamic solution to the differentialintegral equation of the kicker (for large $I_{c}$ ) to assess the risetime of the beam on exit of the kicker [3].

$$
x(z=l, t)=\frac{c^{2}}{4 V_{0} l} \int_{t-2 l / c}^{t} V_{p}\left(t^{\prime}\right)\left(t-t^{\prime}\right) d t^{\prime}
$$

This equation yields for an ideal square pulse

$$
x(z=l)=\frac{V_{p}}{2 V_{0}} l
$$

Assuming a linear rising edge of the pulser with a rise time (from 0 to maximum) of $\tau_{\text {pusser }}$ using eqn. (), the rise time of the beam as it switches from one position to another is

$$
\tau_{\text {healn }}=\tau_{\text {pulser }}+2 l / c
$$

where $c$ is the speed of light in free space.

\section{PULSER DEVELOPMENT}

\subsection{Pulsers on ETA-II}

Two new hard tube modulators have been added to two existing kicker pulsers used for experiments on ETA-II. A total of four pulsers drove the four plates of the kicker to produce kicks in both $x$ and $y$ direction simultaneously.

\subsection{Plans to produce solid state pulsers}

Due to unreliable supplies of fast vacuum tubes, an effort to develop and deliver pulsers based solely on solid state technology is underway.

\section{NEW EXPERIMENTAL DATA}
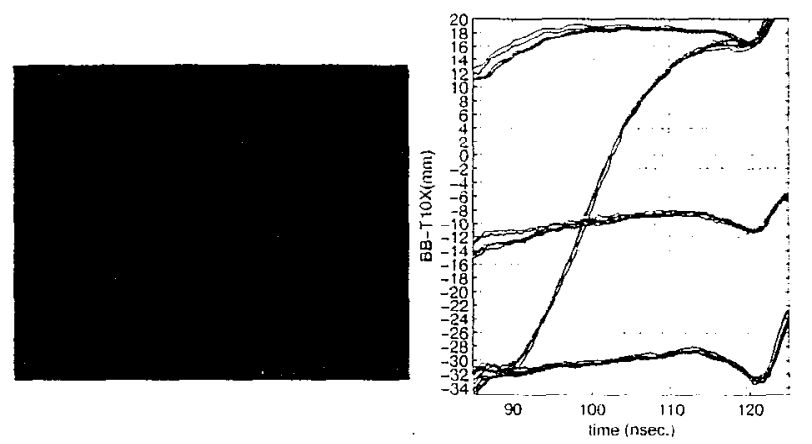

\section{I Kicker dipole measurements}

Fig. 3 Photo and beam bug data of beam switching from one position to another. $I_{b}=1200 \mathrm{~A}, V_{p}= \pm 9 \mathrm{kV}$, camera gated over entire beam pulse, and $\Delta x=4 \mathrm{~cm}$.

\subsection{Kicker quadrupole measurement}
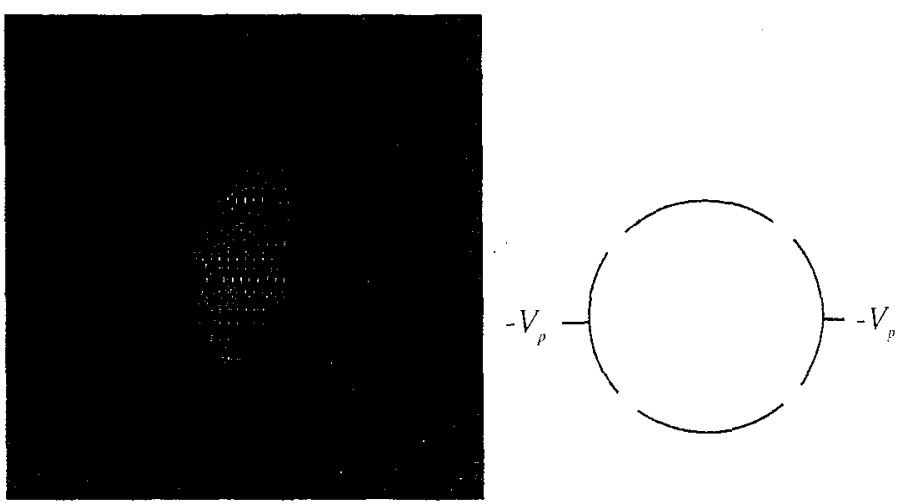

Fig. 4 When the polarity of the pulser signals are the sanie, a quadrupole instead of a dipole field is conned. The photo is for a beam current of $1200 \mathrm{~A}$ and $V_{p}=-10 \mathrm{kV}$ and the ratio of major to minor axes is $2: 1$.

\subsection{Kicker emittance measurements}

Emittance measurements using a pepper pot method [5] whereby the beam impinges on a grid of holes the 
pepper pot mask) and the beamiets which survive are allowed to drift a distance. The amount the beamlers expand is used to calculate beam emittance.

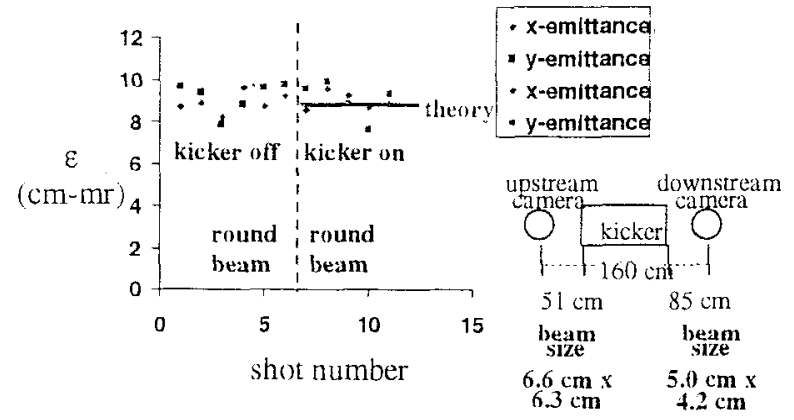

(a)

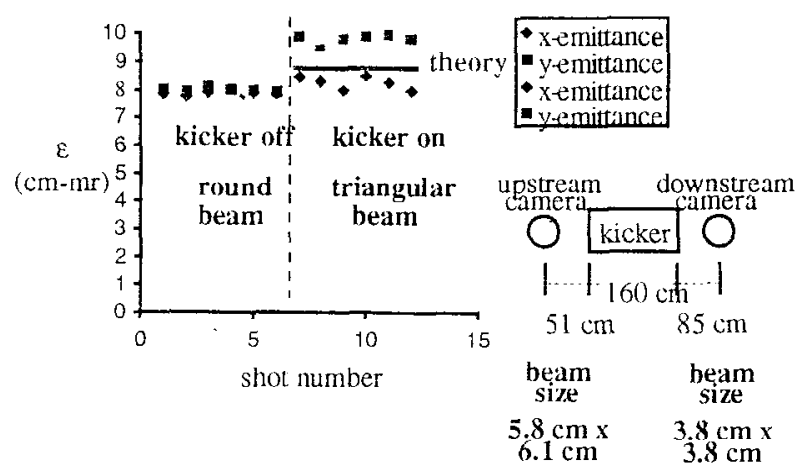

(b)

Fig. 5 Emittance measured downstream of the kicker with and without an applied voltage. (a) A round beam at the output yielded no emittance growth. (b) A larger beam yielded some emittance growth. The y-emittance is slightly larger than in $x$ which is predicted by theory.

\subsection{Kicker control system}

A kicker control system that attempts to regulate beam motion with the dynamics of the kicker has been designed and tested on ETA-II.

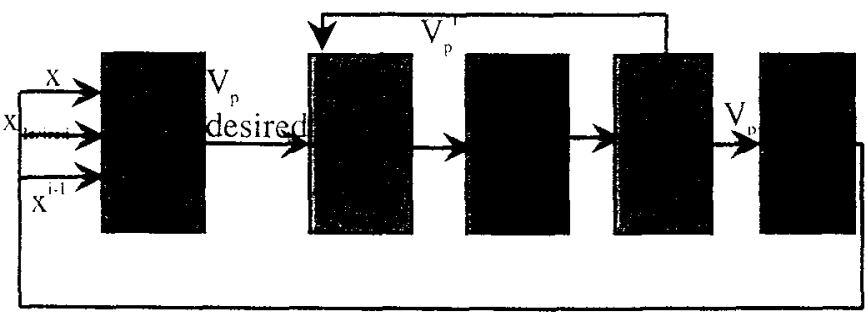

Fig. 6 The beam control algorithm (BCA) takes measured beam location to find the desired voltage needed for the next correction. It then feeds into the pulser control algorithm (PCA) which trys to produce the desired waveform at the output of the pulsers via the arbitrary waveform generators (AWG). Each pulser is controlled independently.

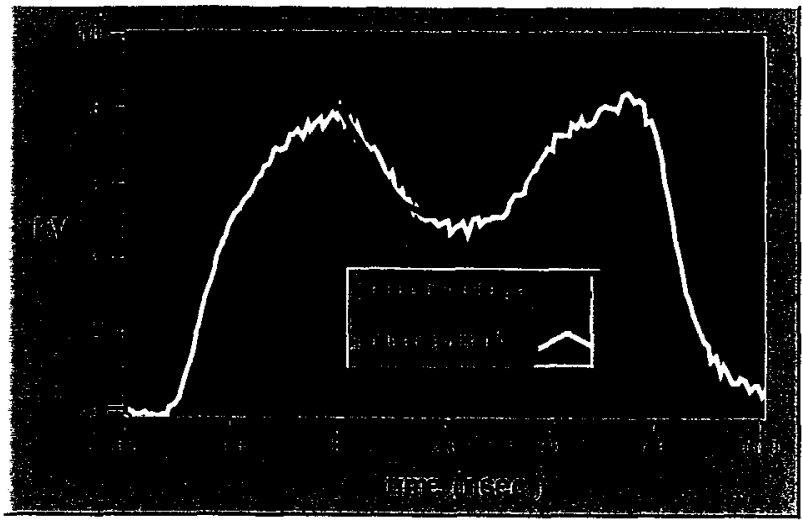

Fig. 7 The desired voltage is achieved at the output of the positive pulser (similar for the negative pulser) to within $2 \%$. Notice the waveform at the tail end has a steep slope that the pulser cannot physically meet.

\subsection{Test of the septum magnet and split beam pipe}

A septum magnet which is capable of generating two opposing dipole field regions was designed and built [6]. A split beam line and the transport section for two diverging beamlines, one straight-ahead and one at $15^{\circ}$ were designed and tested in conjunction with the septum.

\section{CONCLUSION}

Development of a complete kicker system is well underway. The kicker structure itself and the septum magnel have been designed and test on ETA-II. The two components are well-characterized. The control system has been implemented and is undergoing further refinements. A new generation of solid state pulsers is being pursued. Long pulse precision beam position monitors for beam steering throughout the kicker system have been developed and scheduled to be tested on ETAII later this year[7].

\section{ACKNOWLEDGEMENT}

Thanks go to the ETA-II staff for their support of the kicker experiments

\section{REFERENCES}

[1] DeHope, W.J. et. al, to be presented at the $12^{\text {th }}$ IEEE Int'l. Pulsed Power Conf., Monterey, CA, June 1999.

[2] Caporaso, G.J. et. al, 1997 Particle Accelerator Conference. 1861-3, Vancouver. Canada. May 1997

[3] Chen, Judy et. al. "Fast kicker for high current. continuous beam". to be submitted, preprint avail. upon request

[+] Weir. J.T. et al., this conference.

[5] Paul, A.C

[6] Wang, L.F. et al.. this conference.

[7] Nelson, S.D. et al., this conference. 